DOI 10.37882/2223-2982.2021.03.25

\title{
СТАНОВЛЕНИЕ И РАЗВИТИЕ МЕДИЦИНСКОГО ЖАНРА «ЛЕКАРСКАЯ СКАЗКА» В ДОКУМЕНТАХ «АПТЕКАРСКОГО ПРИКАЗА» XVII В.
}

\section{ESTABLISHMENT AND DEVELOPMENT OF THE MEDICAL GENRE "MEDICINAL TALE" IN THE DOCUMENTS OF THE PHARMACEUTICAL ORDER OF $17^{\text {TH }}$ CENTURY}

\section{O. Olekhnovich \\ O. Antsiferova}

Summary: The article presents the results of the linguistic analysis of the medical genre «medicinal tale» based on the material of the "Documents of the Pharmaceutical Order» of the 17th century. More than 50 «medicinal tales» of various subjects - medical certificates, healers' opinions on request, referrals for treatment, less often case histories were used for the study. The tales we are analyzing do not have any attribute in the title; their title is determined by the addresser (healer) or addressers (healers), whose testimony formulates the content of the document. As a rule, trained foreign specialists were the authors of the «tales». The common genre features of the "medicinal tales» (a set of document details arranged in a set sequence) as well as their distinctive features (volume, content, and structural organization) were identified. The formation of the document «medicinal tale» was significantly influenced by medical texts in Latin, the so-called «doctor's tales», which created a certain «language stereotype». This is due not only to the harmonization of inter-language means, which are of Greek and Latin origin, but also to the organization of the text. Due to the weak terminology in the documents, internal language tools were mainly selected. A distinctive feature of fairy tales is the lack of nominativity, the use of predicative descriptions instead of terminological designations.

Keywords: medicinal tale, documents of the Pharmaceutical order, medical genre, healer.

\author{
Олехнович Ольга Георгиевна \\ К.филол.н., доцент, Уральский государственный \\ медицинский университет, г. Екатеринбург \\ olgaolech@yandex.ru \\ Анциферова Ольга Николаевна \\ К.филол.н., дочент, Уральский государственный \\ медицинский университет, г. Екатеринбург \\ antsiferovaon@yandex.ru
}

Аннотация: В статье представлены результаты лингвистического анализа медицинского жанра «лекарская сказка» на материале «Документов Аптекарского приказа» XVII века. Для исследования было использовано более 50 «лекарских сказок» различной тематики - медицинских справок, заключений лекарей по запросу, направлений на лечение, реже историй болезней. Анализируемые нами сказки атрибута в названии не имеют, их название определяет адресант (лекарь) или адресанты (лекари), чьи показания формулируют содержание документа.

Как правило, авторами «сказок» являлись подготовленные зарубежные специалисты. Были выявлены общие жанровые черты «лекарских сказок» - совокупность расположенных в установленной последовательности реквизитов документа, а также их отличительные особенности - объём, содержание, структурная организация. На формирование документа «лекарская сказка» значительное влияние оказали медицинские тексты на латинском языке, так называемые «докторские сказки», которые создавали некий «языковой стереотип». Это связано не только с гармонизацией межъязыковых средств, которые имеют греко-латинское происхождение, но и с организацией текста. В силу слабой терминологичности в документах отбирались в основном внутренние языковые средства. Отличительной особенностью сказок является недостаток номинативности - использование предикативных описаний вместо терминологического обозначения.

Ключевые слова: лекарская сказка, документы «Аптекарского приказа», медицинский жанр, лекарь.
$\Pi$ ериод XVII века в России можно охарактеризовать как ситуацию эволюции научной мысли в области медицины. Именно в это период медицина стала формироваться как самостоятельная дисциплина. Этому способствовало создание государственного медицинского учреждения - Аптекарского приказа, который распоряжался всем медицинским делом. В условиях сложившейся документно-приказной системы для обслуживания новой дисциплины создаются медицинские документы. До XVII века в России были известны в основном тексты компилятивного характера (лечебники и травники). В период XVII века происходил постепен- ный перенос акцента на творческий характер языкового акта. На это указывали многие исследователи. Так, Вяч. Вс. Иванов отмечал, что «установка заключается не в сохранении уже существующего текста, а в создании нового, который должен быть принципиально отличен от всех ранее существовавших...» [4, с. 9].

Из медицинских документов актовой письменности основная нагрузка ложится на «сказки». В отличие от компилятивного текста «сказка» - созидательный документ. Жанровая разновидность этого документа деловой письменности начинает формироваться в конце XVI 
века. Свое название она, вероятно, получила в результате исторического развития слова 'съказъ' «повьствованіе, сказаніе; - объясненіе, толкованіе» [10, с. 715]. Словарь А.Л. Дювернуа дополнил «Материалы ...» И.И. Срезневского: «составляемый по требованию администрации или суда документ, содержащий известные его автору сведения о деле». «Сказка - indicium и narratio» [3, с. 188] «indicium,-i n заявление, показание, донос» [2, с. 392]; «narratio,-onis f повествование, рассказывание чего-нибудь, подробность какого-нибудь случившегося или могущего случиться действия, дела» [6, с. 78]. K XVII веку «сказка» становится довольно употребительным словом и активно используется во многих значениях. Отметим основные значения: «1. Рассказ, сообщение. 4. Заявление, показание; тж. название различных документов делопроизводства, содержавших показания свидетелей, отчеты, донесения о событиях, происшествиях, торгах, о выполнении служебных и прочих поручений, доносы на кого-л. [9, с. 169]. Качалкин обобщил особенности жанра: «Сказки - это письменные показания по определенному вопросу. Подавались они по разным поводам, когда администрации нужны были сведения по какому-либо делу, известные авторам сказок» [5, с. 82].

В документах Аптекарского приказа «сказка» тематически расширяет свои границы. Многие из них приобретают узкую профессиональную направленность и используются в качестве медицинского документа. В частности, более 200 «сказок» относятся только к медицинской тематике.

Большинство исследуемых документов имеют самоназвания. Видовое обозначение определяет адресант или адресанты, чьи показания формулируют содержание документа. Параметр «адресант» определяет три основные разновидности - доктор создавал докторские сказки, лекарь - лекарские сказки, аптекарь - anтекарские сказки. Они отличаются друг от друга содержанием, объёмом и структурной организацией. С содержательной стороны выделяются несколько разновидностей: докторские сказки - истории болезней, рекомендации о лечении болезней, рецепты приготовления лекарств, показания докторов об освидетельствовании; лекарские сказки - медицинские справки и заключения; аптекарские сказки - росписи о составе и приготовлении лекарств.

Для анализа нами было выбрано более 50 лекарских сказок. Это в основном медицинские справки и заключения, в которых представлены описания болезней и повреждений, а также результаты обследования и заключения.

Для анализа нами были использованы рукописи Аптекарского приказа периода XVII века, хранящихся в Российском государственном архиве Древних актов в г. Москве (Фонд 143, 2724 ед. хр., 1629-1716 гг.) [8], а также документы, опубликованные Н.Е. Мамоновым в С.-Петербурге в 1881-1885 гг. «Материалы по истории медицины в России», вып. I-IV [7]).

Лекарские сказки атрибута в номинации не имеют, их название определяет адресант - лекарь (Сказка лекаря Албануса о непригодности к службе капитана Якова Чирикова $[8,578])$ или адресанты - лекари (Сказка лекарей Симона Зоммера, Ив. Албануса, Ив. Островского, Дан. Фон Гадена, Артемья Назарьева о болезни Ив. Cmen. Панова $[8,722])$

Лекарские сказки в документах представлены в двух вариантах - как самостоятельный документ и как составная часть документов («Дело», «Список»).

К оформлению документов допускались только лекари-иностранцы, получившие медицинское образование.

В Допросных речах новопризнанных лекарей сообщаются некоторые сведения о лекарях: «Юрья Мартыновъ сынъ Гансенъ родился въ Датикой земли; а лекарскому дгллу учился въ городъь Вилнг девять лгтъ...служиль королю швецкому годъ у курфирста брандебурского два года, а лгкарскому дглу научился: раны колотые и ргззаные и стрголеные и пулки выргызывать, и костоправное дъъло и очную бользнь лгъчтыь.

Отто Эймерсъ родился въ Датцкой землг лгькарскому дъълу учился въ той же земль; служил въ Амбурхг и въ иныхъ городахъ года съ четыре и болши и всякіе лгккарскіе части научился...» [8, 1281].

Именно в лекарской сказке формируется новый речевой этикет, отличительной особенностью которого является присутствие медицинской лексики. Структура лекарской сказки напоминала структуру сказки, включающую в себя реквизитную, основную и заключительную часть. Первая часть начиналась с даты (1); основная часть обычно состояла из вводной, где указывался адресант (должность, фамилия имя и данные о больном) (2) описательной (симптомы, признаки болезней) (3) и эпикризной (заключение) (4), третья - заканчивалась подписью лекаря (5) и указанием на адресата (6).

Сказка лекаря Ив. Албануса о непригодности к службе капитана Чирикова $[8,578]$.

170 г. (1662) Іюля въ 1-й день (1). Лгькарь Иванъ Албанусъ смотря бользни маерова полку Ивана Воронина капитана Якова Тимофъвева сына Чирикова, (2) сказал, что у него правая рука выше локтя переломлена пополамъ и жилы перерваны, и тое руку у него свело, (3) а излечить тое руки у него не мочно жъ, потому что та бользнь 
застарголась. (4)

Послана такова скаска въ Иноземской Приказъ (6) за рукою лекаря Ивана Албануса (5).

Пример другой сказки - своебразный отчет лекаря о личных достижениях - Сказка окулиста Иоганна Шартлина о вылеченных им больных [8, 1182].

185-го Апргля въ 30 день въ Оптекарскомъ Приказґ боярину Князю Никитгъ Ивановичю да кравчему съ путемъ ко Князю Василью Федоровичю Одоевскимъ да дьяку Левонтию Меншову, лекарь и окулистъ очной мастеръ Яганъ Тарихъ Шартлинъ сказал: пригхал де онъ въ Московское Государство излечиль на Москвъ: боярина Князя Якова Никитича Одоевского дочь: не видгъла очми (1), а нынгъ видитъ (3).

Юоярина жъ Князь Юрья Алексъвевича Долгоруково -у жены ево...глаза вылечиль (3), а испорчены де были оть нашатырю (5), что пускали ей прежь сего незнающіе люди нашатырь въ глаза (1) .

Думного дворянина и ясельничаго у Ивана Tимофеевича Кондырева, у сестры ево глаза вылечиль (3); росъ влосъ (1) , и тотъ волосъ выргзывваль (2).

у боярыни Княгини Фетиньи Ивановны Лобановой глаза вылечилъ: шла слеза (1), а нынъ слеза нейдет (3), а нынгь лечитъ своимъ лекарствомъ (4). тускъ (1) вылечиль (3): тускъ согналъ з глазъ.

Таково писмо отдано дьяку Леонтию Меншову того жъ числа.

Достижения лекаря выражены соотношением двух категорий «болезнь» - «здоровье». Больной при помощи лекаря проходит несколько стадий от состояния болезненного состояния (1) > лечения (2) > до выздоровления (3), и при необходимости дальнейшего лечения (4). Очень редко лекарь указывает на причины заболевания (5), поскольку это было прерогативой докторов.

Часто лекарские сказки входили в состав более сложного документа.

Формуляр такого документа состоял из двух частей: документа распорядительного характера - Памяти и Лекарской сказки. Память включала в себя довольно много реквизитов: дату подачи документа (1), заголовок (2), адресант (или адресанты), который обычно содержал указание на имя и титул т (3), адресат (4) указная цель (как правило, осмотр) (5), фамилия, имя больного (6): медицинская справка (7) имя нового адресата (или адресатов) (тот, кому нужно справку переслать) (8) Подпись дьяка (9).
Дело об осмотре увечного стрельча Саввы Сущевского $[8,846]$.

Лrъта 7177-го (1669) Апрголя въ 28-й день (1) по Государеву Цареву и Великого Князя Алексъв Михайловича указу (2) околничему Ивану Михайловичю Милославскому да дьяку Ивану Десятово (3) Великій Государь въ Оnтекарскомъ Приказе лгккаремъ (4) осмотрить (5) увечного стрельча Саввы Сущевского (6): чгыз онъ увъьченъ, и Великого Государя службу служить не мочно-ль или не мочно (7) да тотъ осмотръ... приказаль прислать в Стргљлецкий Приказъ...къ думному Олександру Дурову (8) Діякъ Иванъ Горяиновъ (9).

Память напоминала о том, что все действия лекарей подотчетны, т.е. их деятельность находится под пристальным вниманием.

Лекарская сказка по своей структуре напоминала самостоятельный документ, она включала в себя реквизитную (дату) (1), основную (адресант и данные о больном) (2), описательную (симптомы, признаки болезней) (3) и эпикризную (заключение) (4), наконец, заключительную часть (подпись лекаря) (5) и указание на адресата (6). Правда, в реквизитной части появляются дополнительные сведения, связанные с первой частью документа (Памяти) - куда, откуда и за чей подписью поступают указные документы.

177-го (1669) Апрголя въ 28-й день (1) въ Оптекарскомъ Приказе по памяти изь Стрголечкого Приказу за приписью діяка Ивана Горяинова, лгкарь Иванъ Албанусъ... стрельча Савку Сущевского (2) осматриваль, а по осмотру сказаль что у него правая рука изъ плеча вышибена (3)и не владъетъ (4). Подпись: Johan Albanus (5) (3а симъ согласно выше приведенной сказки следует отписка в Стрголецкий Приказъ) (6).

В качестве опорных звеньев рассмотренныхтекстов выступает не только медицинская лексика, но и стереотипные выражения - осматриваль, смотря болъзни, за рукою лекаря, лечить не мочно, бользнь застаргла.

В обоих документах компоненты формуляра не выделены из текста. Логичность и связность тексту придавали вводные слова, указательные местоимения (сей, тотъ); усилительные (же) и отрицательные частицы (ни...ни); наречия (отсюду). Отметим, что в тексте активно используются повествовательные и в основном сложноподчиненные предложения с союзами что, как, потому что, не очень характерные для русского языка периода XVII века.

И лькари Симонъ Зоммеръ, Иванъ Албанусъ, Иванъ Островский, Данило Фунгадановъ, Артемей Назарьевъ, 
смотря Ивановой бользни Степанова, сказали, что у него изъ нутрии выходятъ черева въ тайные уды; и сказал он Иван, что у него тrъ черевы выходятъ тому 4-й годъ; и имъ де ево Ивана лечить не мочно, по тому что болґзнь застаргла. Сказка лекарей Симона Зоммера, Ив. Албануса, Ив. Островского, Дан. Фон Гадена, Артемья Назарьева о болезни Ив. Степ. Панова [8, 722].

В сказке могли указываться рекомендации для больного - здгълать поясъ широкой, и тъвъ поясомъ то мгссто подвязывать, и быть дома, и никуды ходить и гъздить не мочно [оп. II, л. 722].

Анализ механизмов формирования лекарской сказки показывает, что они достаточно информативны, им характерна не только связность и целостность, но и более или менее упорядоченная структура и стилистическая завершённость. Правда, необходимо отметить, что не все критерии текстуальности проявлялись в полной мере. Низкая интенциональность лекарской сказки связана с уровнем развития науки.

Сказки выполняли информационную функцию, поскольку цель документа состояла в представлении необходимой по какому-либо делу информации. Этот параметр реализуется в тексте посредством глагола, обозначавшего коммуникативное действие, часто сочетавшегося с самоназванием документа: сказкой сказали, сказку дали.

Авторы лекарских сказок для разных событий используют единый формуляр. С одной стороны, трафаретность документа несколько ограничивает мышление автора; с другой стороны, она подводит его изложение в нужные рамки. Среди возможных вариантов он избирает языковые средства, наиболее соответствующие стилю данного жанра документа. При изучении разных лекарских сказок были найдены общие и отличительные признаки.

Лекарские сказки в виде справок в большом количестве были представлены и в других документах - например, в Списках больных, где обычно указывались весьма лаконичные описания: раненъ въ правое стегно изъ лука; рубленъ саблею въ шти мгстехъ по головъ да по правому плечю, да лґвая рука выше локтя пробита на сквозь, да пулкою въ голову подль львого глаза; зашибенъ по львой руке по мышкъь каменемъ; опалило лицо порохомъ турецкимъ; перерублена шея до кости [оп. II, л. 850].

В документах такого типа часто использовалась терминологическая лексика с недостатком номинативности - огневая (вместо 'огневая болезнь (вид инфекционной болезни с высыпаниями на коже'); голова зашибена (вместо 'ушиб головы'), ноги опухли (вместо 'опухоль ног').
Терминологически значимыми в тексте становятся глаголы или глагольные фразеологизмы (лежитъ при смерти, кончается; небо осыпалось становые жилы свело, сухія жилы ведетъ; ноги и руки трясутиа; середний перстъ оторвало виситъ на кожъ и у перстовъ у встьхъ жилы портило; да у правой руки издробило кости; и глазб вышибло лгвой и лобъ изломало). Реже используются краткие прилагательные (желудокъ и печень и селезенокъ безсильны, печень и селезенка заперты, рана болна, раны тяжелы). Полные прилагательные выполняют роль определения к слову 'болезнь' (у него бользнь чечюйная) или к названию определенных болезней или их симптомам, указывающим на степень тяжести заболевания ( на руках опухоль великая; тяжелыми ранами).

Недостаток терминологичности автор «исправляет» различными способами. Несмотря на некоторую случайность употребления терминов, мы видим, как автор стремится к точности воспроизведения анатомических названий, прибегая к помощи предлогов (раненъ стрглою въ поясницу противъ живота); уточняющих прилагательных раненъ въ лгвую руку по болшому персту; въ мизиной перстъ); прилагательных сравнительной степени (раненъ въ лъвую пониже колъна; правой рукъ ниже плеча по мышкъ). Кроме этого, используются слова с количественным значением (рубленъ саблею въ двум мсттьхъ, да у лъвой же руки порублены два перста середнихъ).

Репрезентативные возможности у каждого автора индивидуальны, поэтому, так или иначе, внутри жанра они создавали варьирование языковых средств, но такие внедрения в структуру текста не являлись препятствием.

Несмотря на то, что русский язык в XVII в. еще окончательно не сформировался, языковая вариативность, непоследовательность номинации от экономичных до громоздких наименований, не помешали заложить основы организации специального текста. Медицинская документация постепенно выделилась в отдельную группу со своими характерными номинативными и функциональными особенностями, выполняя свою особую терминологическую роль в языке медицины рассматриваемого периода.

Документы Аптекарского приказа с одной стороны, представлены традиционными документами делового жанра; с другой стороны, они имеют узкую профессиональную направленность, поэтому ограничены специальными средствами, связанными с медициной.

Несмотря на тематические различия и многочисленные варьирования документы четко структурированы. Именно в этом компоненте проявляется тенденция к унификации документов. 


\section{ЛИТЕРАТУРА}

1. Виноградов В.В. История русского литературного языка. М.: Наука, 1978.

2. Дворецкий И.Х. Латинско-русский словарь. М.: Русский язык, 2000.

3. Дювернуа А.Л. Материалы для словаря древнерусского языка. М.: Университетская типография, 1894.

4. Иванов В.В. О взаимоотношении динамического исследования эволюции языка, текста и культуры. // Исследования по структуре текста. М.: Наука, 1978.C. 5-26.

5. Качалкин А.Н. Жанры русского документа допетровской эпохи. Часть ІІ. М.: Издательство Московского университета, 1988.

6. Кронеберг И.я. Латинско-российский лексикон. М.: Типография Семена Селивановского, 1834.

7. Материалы по истории медицины в России // Вестник судебной медицины и общественной гигиены. 1883; 3: 23-36; 4: 42-46; 1884; 3: 55-61; 1885; 1 : 19-22, 2: 62-71.

8. Российский Государственный Архив Древних актов (РГДДА). Фонд (Ф.) 143. Опись (Оп.) 2. (1629-1716).

9. Словарь русского языка XVII-XVII вв, вып. 24. Москва: Наука, 2000.

10. Срезневский И.И. Материалы для словаря древнерусского языка по письменным памятникам. Том III. Санкт-Петербург: Типография Императорской Академии наук, 1912.

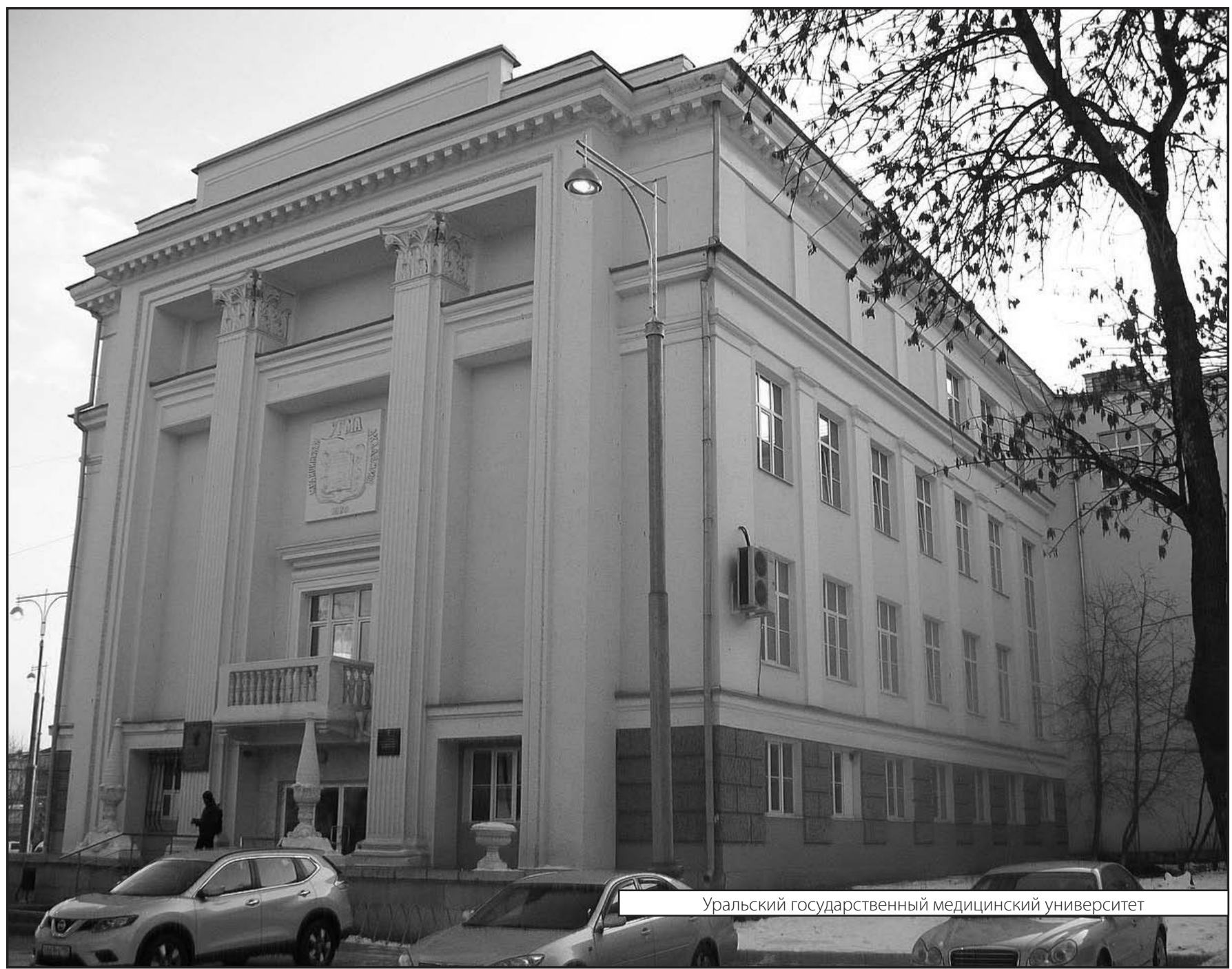

